\title{
PENINGKATAN KUALITAS SEKTOR INFORMAL SEBAGAI STRATEGI MODIFIKASI POLA PERILAKU WARGA DI KELURAHAN MANGGA BESAR
}

\author{
Neilsen Yonata ${ }^{1)}$, Denny Husin ${ }^{2)}$ \\ 1)Program Studi S1 Arsitektur, Fakultas Teknik, Universitas Tarumanagara, neilsenmandela@gmail.com \\ 2)Program Studi S1 Arsitektur, Fakultas Teknik, Universitas Tarumanagara, denny@ft.untar.ac.id
}

Masuk: 13-07-2020, revisi: 31-07-2020, diterima untuk diterbitkan: 24-09-2020

\begin{abstract}
Abstrak
Fenomena yang diangkat dalam studi adalah proses adaptasi Kelurahan Mangga Besar dari permasalahan yang ada di kota terkait stress karena peningkatan jumlah penduduk secara signifikan. Kelurahan Mangga Besar merupakan salah satu tempat kuliner terbesar yang ada di Jakarta oleh sebab itu banyak pengunjung yang datang ke tempat ini untuk mencari makan dan juga mencari tempat hiburan. Kepopuleran kawasan Mangga Besar menyebabkan timbulnya masalah pada kelurahan ini. Salah satunya adalah peningkatan sektor informal berupa pedagang kaki lima dan juga tempat parkir ilegal yang mengakibatkan kemacetan. Kawasan Mangga Besar memiliki karakteristik berupa sektor informal yang mempengaruhi aktivitas keseharian di Kelurahan Mangga Besar. Tujuan studi berfungsi untuk menyikapi informalitas dengan sistem agar mempengaruhi human behaviour seseorang dengan menggunakan metode pendekatan urbanism yang dimana melihat dari perkembangan di suatu kota yaitu Jakarta yang mempengaruhi perilaku seseorang. Secara hipotesa dengan menambahkan sistem terintegrasi akan merubah human behaviour seseorang, menghilangkan parkiran ilegal, dan mengatur informalitas yang ada di Mangga Besar. Langkah yang digunakan yaitu menghadirkan sistem berupa cycle sistem yang dapat di reuse kembali dan menambahkan sistem belt untuk mempengaruhi human behaviour. Dengan cara ini didapatkan bahwa manfaat proyek ini berfokus untuk memberikan manfaat terhadap skala wilayah yang diharapkan dapat meningkatkan kemudahan dalam segi transportasi, kesejahteraan, serta mempengaruhi kebiasaan manusia dengan sistem. Hasil yang di dapat pada proyek ini adalah menghadirkan akses bagi user dari kelurahan ke transportasi umum, mempunyai living space yang dapat digunakan untuk berjualan, memiliki sarana hiburan berupa tempat third place, meningkatkan keseimbangan sosial bagi kelurahan ini.
\end{abstract}

Kata kunci: Perilaku manusia; Kuliner; Keberagaman; Tempat ketiga

\begin{abstract}
The phenomenon chosen is the Mangga Besar which adapts to the differences in the city, namely stress due to a significant increase in population. Mangga Besar sub-district $d$ is one of the biggest culinary places in Jakarta, therefore visitors who come to this place to find food and also look for places of entertainment because of the causes that cause problems in this village. Among other things, there is an informal improvement sector that sells street vendors and also illegal parking lots that cause congestion. Therefore the issue in this region has the characteristics of the informal sector that affects daily activities in the Mangga Besar The purpose of the research works to address informality with the system to improve one's human behaviour by using the method of urbanism that looks at developments in which cities in Jakarta affect one's behaviour. Hypothetically added that an integrated system will change one's human behaviour, eliminate illegal parking, and the informality that exists in large mangoes. The language used is to present a system consisting of a cycle system that can be reused then can be reused and add a belt system to change human behaviour. In this way, the Project benefits needed to provide benefits to the scale of the region are expected to increase comfort in terms of transportation, welfare, and improve human efficiency with the system. The results that can be obtained from this project are giving users access from the sub-district to public transportation, having a living room that can be used to sell, having access to third place, increasing the social balance for this sub district.
\end{abstract}

Keywords: Human behavior; Culinary; Diversity; Third place 


\section{PENDAHULUAN}

\section{Latar Belakang}

Jakarta merupakan ibukota Indonesia yang difungsikan sebagai pusat pemerintahan, bisnis, sosial, serta sebagai tempat pertumbuhan ekonomi, oleh sebab itu perkembangan ibukota sangatlah signifikan dari moda transportasi dan juga pertumbuhan penduduk. Pertumbuhan penduduk mengakibatkan banyaknya kemacetan yang ada di Jakarta, yang mengakibatkan banyak penduduk yang stress akibat kemacetan dan tingkat kepadatan yang tinggi. Banyaknya penduduk yang stress mengakibatkan adanya pola gaya hidup untuk mencari tempat hiburan guna menghilangkan stress Salah satunya Kelurahan Mangga Besar yang banyak mengadaptasi dari permasalahan yang ada di kota Jakarta.

Kelurahan Mangga Besar merupakan salah satu tempat kuliner terbesar yang ada di Jakarta. Banyak pengunjung yang datang ke tempat ini untuk mencari makan dan juga mencari tempat hiburan. Dikarenakan banyaknya tempat hiburan Kelurahan Mangga Besar mengalami peningkatan sektor informal berupa pedagang kaki lima dan juga tempat parkir yang melanggar aturan; aktivitas yang ditimbulkan oleh sektor informal ini menyebabkan Kelurahan Mangga Besar memiliki human traffic yang tinggi. Mangga Besar sudah memiliki sistem transportasi berupa stasiun Mangga Besar, halte Busway Olimo, mikrolet, dan juga ojek daring. Hal ini menyebabkan Kelurahan Mangga Besar sangat macet dan juga tidak teratur.

Fenomena yang diangkat adalah Kelurahan Mangga Besar yang dimana banyak mengadaptasi dari permasalahan yang ada di kota lewat banyaknya tempat makan (Street food), tempat bermain billiard, tempat pijat, tempat rekreasi, dan juga club malam oleh karena itu daerah Mangga Besar memiliki human traffic yang tinggi. Mangga Besar sendiri mempunyai karakter yang sangat kuat dengan dunia malam dan kuliner serta banyaknya (Warga Negara Asing) yang tinggal disana salah satu nya WNA (Warga Negara Asing) dari China. Mangga Besar juga memiliki data lokasi yang terdiri dari perusahaan, fasilitas hiburan, rasio banyaknya hotel di Mangga Besar, data pangkalan ojek, data tempat kuliner dan data tempat berbelanja. Dari fenomena yang di dapat dapat di simpulkan bahwa kawasan Mangga Besar akan berfungsi sebagai tempat Streetfood yang mengayomi semua usia dari anak-anak sampai lansia sehingga ruang yang di hadirkan di adaptasi dari perilaku manusia serta informalitas yang ada di Mangga Besar berupa sistem portable berupa ruang publik, area makan, dan area olahraga hal ini tidak hanya itu saja sistem juga mempengaruhi human behaviour seseorang berupa sistem self service yang dimana makanan dapat diantarkan dengan sistem belt di plafond bangunan

Jakarta tidak terlepas dari kejenuhan akan rutinitas serta aktivitas keseharian yang padat yang dapat menimbulkan stress. Oleh sebab itu, banyak sekali orang yang mencari kesenangan agar terhindar dari masalah tersebut dengan mencari tempat makan, tempat refreshing, serta tempat hiburan malam.

\section{Rumusan Permasalahan}

Permasalahan di Kelurahan Mangga Besar pada umumnya terjadi dikarenakan banyaknya sarana atraksi yang mengakibatkan meningkatnya pengunjung yang sangat banyak yang menimbulkan permasalahan antara lain:

a. Belum adanya sarana menunggu bagi kalangan pekerja pada waktu rush hour yang menyebabkan kurangnya interaksi antara masyarakat di mangga besar yang berdampak kepada faktor psikologi.

b. Belum adanya ruang publik yang menunjang dan mewadahi masyarakat yang bekerja Dan tinggal di Mangga Besar sehingga menggunakan pedestrian, gang-gang kosong, bahu jalan dan dan jalan-jalan kecil sebagai wadah social informal.

c. Terdapat zona red district (aktivitas yang dimana tingkat prostitusi tinggi )pada tapak. 
d. Terdapat informality (informalitas merupakan unit-unit usaha tidak resmi berskala kecil yang menghasilkan dan mendistribusikan barang dan jasa tanpa memiliki izin usaha dan atau izin lokasi berdasarkan ketentuan peraturan perundang-undangan yang berlaku) pada malam hari.

e. Banyak nya tempat parkir illegal (menggunakan bahu jalan, gang-gang kosong, dan jalan jalan kecil) yang membuat mangga besar menjadi tempat yang sangat macet saat jam jam tertentu.

f. Adanya kesalahan fungsi dalam penggunaan jalur lambat pada mangga besar raya yang dimana jalur lambat yang ada di mangga besar dijadikan tempat parkir dan tempat berjualan.

g. Belum adanya sarana menunggu bagi kalangan pekerja pada waktu rush hour yang menyebabkan kurangnya interaksi antara masyarakat di mangga besar.

h. Banyaknya ojek online yang memangkalkan motor dan mobil dengan sembarangan.

Permasalahan yang diangkat dari isu kemudian disesuaikan dengan kawasan yang menghadapi permasalahan yang sama. Sehingga terdapat beberapa rumusan dari permasalahan yaitu :

a. Menyikapi informalitas dengan sistem agar memepengaruhi human behaviour seseorang

b. Bagaimana menghadirkan third place agar dapat menjadi program penunjang bagi masyarakat Kelurahan Mangga Besar serta membuat bangunan arsitektur menjadi sarana pembelajaran dan dapat menyikapi kebutuhan masyarakat

c. Bagaimana menghadirkan shortcut dari jalan besar ke jalan kecil untuk mengurangi human traffic serta memudahkan aksesibilitas dari kelurahan ke transportasi umum dan menghilangkan parkiran illegal

\section{Tujuan}

Tujuan proyek ini lebih berfokus pada Kelurahan Mangga Besar yang dimana proyek arsitektural yang akan di bangun dapat membantu dalam mempermudah akses pejalan kaki dan juga menghilangkan kasus kemacetan yang terjadi pada jam padat (rush hour.) Kemudian tujuan perancangan proyek ini memberikan manfaat terhadap skala wilayah yang diharapkan dapat meningkatkan kesejahteraan warga RW 05 terutama dalam hal mengakses ruang untuk bersosialisasi, bermain, berekspresi, sehingga orang tua tidak merasa cemas akan anaknya yang bermain di jalanan, anak-anak pun dapat nyaman bermain, serta lansia yang tadinya menghabiskan aktivitasnya di dalam rumah kini bisa beraktivitas di luar rumah. Untuk skala kota manfaatnya dapat menciptakan pusat destinasi baru, sedangkan untuk masa depan diharapkan menjadikan DKI Jakarta yang lebih baik dan berkelanjutan. Dengan cara :

a. Membuat Program yang bekerja dengan sistem agar mempengaruhi human behaviour seseorang agar dapat meunjang kebutuhan, sarana edukasi, tempat hiburan bagi Kelurahan Mangga Besar

b. Membuat tempat yang dapat meningkatkan keseimbangan sosial

c. Menyediakan tempat yang memenuhi standart bagi pejalan kaki dengan merevitalisasi pedestrian serta menghilangkan parkiran illegal untuk menciptakan lingkungan yang tidak macet

\section{KAJIAN LITERATUR}

\section{A Third Place}

Pada masa kini pertumbuhan di kota semakin memicu keberagaman kegiatan salah satunya kencenderungan kegiatan masyarakat kota yang mengharuskan memiliki kebutuhan untuk bertukar informasi serta tempat yang nyaman untuk berkomunikasi serta bersosialisasi. Aktivitas tersebut sering kita dapatkan di rumah maupun di kantor tetapi pada masa kini masyarakat sudah membutuhkan tempat untuk melakukan kegiatan tersebut yang dimana tempat ini disebut tempat ketiga atau third place (Oldenburg, 1989) 
Tempat ketiga / third place merupakan tempat yang memiliki konsep community building yang didasari pada sebuah lingkungan sosial yang memiliki karakter yang berbeda dengan lingkungan sosial yang ada dirumah dan tempat kerja (Oldenburg, 1989). Third place sendiri akan muncul diantara tempat first place dan second place (Oldenburg, 1989). Menurut Oldenburg terdapat tiga kriteria untuk memenuhi kebutuhan hidup dalam place yaitu rumah sebagai first place, tempat kerja sebagai second place dan dibutuhkan third place yang dimana tempat yang dapat menaungi kebutuhan manusia untuk bersosialisasi, berkumpul dan tempat bertukar informasi tanpa memandang status orang tersebut, kemudian terdapat perbedaan karaker untuk antara third place dengan ruang publik. Third place berfungsi sebagai ruang netral yang dapat menyetarakan status sosial sehingga menciptakan ruang untuk melepas stress. Third Place sendiri juga dapat di hubungkan dengan Human Behaviour yang di jelaskan pada buku The Great Good Place (Oldenburg, 1989).

\section{Standard Ruang Makan dan Table Services}

Standard ruang makan sangat dibutuhkan untuk membuat tempat street food, kemudian fungsi dari standar ruang makan sendiri diciptakan dari ruang informal yang ada di Kelurahan Mangga Besar. Table Services adalah suatu sistem pelayanan restoran dimana para tamu duduk di kursi menghadap meja makan, kemudian makanan maupun minuman diantarkan, disajikan kepada para tamu tadi. Dalam hal ini menyajikan makanan dan minuman dapat dilakukan oleh pelayan. Kelebihan sistem ini yaitu pembeli tidak perlu menunggu dan mengambil sendiri makanan yang telah dipesan dari counter dan bisa langsung menunggu pada tempat duduk mereka. Kekurangan sistem ini pihak penjual harus menyediakan tenaga kerja lebih untuk pelayanan pengantaran makanan.

\section{Sirkulasi Radial}

Alur sirkulasi Radial terdiri dari jalur linier yang memanjang yang akan berakhir disebuah titik yang dimana penghujung titik ini menjadi tempat pertemuan atau sebagai titik orang berkumpul untuk berbagi informasi dan bersosialiasasi. Standar Dimensi dan Jarak Sirkulasi antara lain sebagai berikut:

a. Area Makan: 0,83 $\mathrm{m} 2$ perorang, makanan yang disajikan terbatas, dirancang menurut pola yang ada (Ching, 2008).

b. $1,2-1,4 \mathrm{~m}^{2}$ perorang dilayani oleh pelayan.

c. Pergeseran maju mundur kursi antara $100-200 \mathrm{~mm}$ untuk kebutuhan duduk.

d. Pergeseran mundur kursi pelanggan berdiri $300 \mathrm{~mm}$.

e. Antara tempat duduk yang satu dengan tempat duduk yang membelakangi merupakan gang yang disebut jalur pelayanan dengan jarak $1.350 \mathrm{~mm}$.

f. Area Dapur Luas dapur sekurang - kurangnya $40 \%$ dari ruang makan atau $27 \%$ dari luas bangunan.

\section{Elemen Desain}

\begin{tabular}{ll}
\hline Elemen Desain & \multicolumn{1}{c}{ Elemen Arsitektural } \\
\hline Lantai & $\begin{array}{l}\text { Lantai dapat berfungsi sebagai sinyal langsung seperti permukaan halus, kesan elegan, } \\
\text { dan menyerap suara. Penggunaan bahan yang berbeda memberi beragam sensasi pada } \\
\text { pemakai dan juga pola dalam warna di lantai juga dapat berpengaruh dengan tingkat } \\
\text { ketertarikan pengunjung yang datang. }\end{array}$ \\
\hline Dinding & Dinding termasuk pola yang dapat diolah sebagai point of interest, sumber \\
& $\begin{array}{l}\text { pencahayaan, dan interaksi dengan dunia luar. Dinding dari bahan keras cenderung } \\
\text { meningkatkan kebisingan suara, dapat diatasi dengan bahan yang menyerap suara. } \\
\text { Dinding dari segi operasional harus mudah dibersihkan, dan tahan terhadap pemakaian }\end{array}$ \\
\hline Plafon & Pola plafon dimana terdapat cove atau pemasangan lighting cove juga dapat \\
& mengurangi jumlah suara serta permainan ambang atas (drop ceiling ) dapat \\
\hline
\end{tabular}


mempengaruhi mood orang makan kemudian ada beberapa factor yang di butuhkan dalam mendesain street food yaitu pemakaian air control unit, pemakaian sistem heating dan cooling yang dapat di sesuaikan dengan iklim, smoke control digunakan pada area yang mudah terbakar.

Pencahayaan 1) Decorative Luminaries. Penggunaan lampu dekoratif sangat diperlukan untuk meningkatkan dan menonjolkan aksen ruangan pada interior area makan

2) Accent Lighting. Pencahayaan ini merupakan pencahayaan khusus untuk menggunakan spot lighting untuk membantu menampilkan detail eleman dan dekorasi interior.

3) Dimming Possibilities. Pengaturan lampu menggunakan dimmer sangat diperlukan untuk mengatur kuat lemahnya kapasitas cahaya yang diinginkan untuk suatu ruangan

4) Light Integrated with Furniture. Lampu yang digunakan tidak dapat dipisahkan penggunaannya dari perabotan yang ada. Jadi seakan - akan pencahayaan yang ada diperuntukkan untuk perabotan tersebut.

5) Dynamic Lighting. Penggunaan dynamic lighting hampir sama dengan penggunaan dimmer yang dipasang pada pencahayaan.

Warna Warna yang disarankan digunakan pada tempat makan

1) Merah adalah warna yang penuh emosi dan warna yang sangat energik. Warna ini dapat meningkatkan laju pernapasan dan menaikkan tekanan darah. Warna merah cenderung mengarah pada nafsu makan.

2) Hijau Warna hijau terkait dengan alam. Warna hijau adalah warna yang menyegarkan. Penggunaan warna hijau tidak boleh berlebihan karena mempengaruhi penampilan warna kulit dan beberapa makanan. Warna hijau hanya diaplikasikan sebagai warna sekunder pada ruangan untuk memberikan kesan menenangkan dan santai.

3) Coklat menunjukkan maskulinitas menunjukkan kehangatan dan feminimitas. Yang dimana warna ini sebagai kenyamanan dalam ruang makan.

4) Putih efektif bila diselaraskan dengan warna lain. Dinding putih dapat merepresentasikan kecerahan dan suasana bersih.

Sumber: Ching,2008.

\section{Pola Pedangan Kaki Lima}

Menurut McGee dan Yeung dalam (Surya,2006) pedagang kaki lima memiliki 3 pola. Pola tersebut antara lain:

\section{Pola Persebaran Memanjang (linear concentration)}

Pola persebaran ini dipengaruhi oleh pola jaringan jalan. Aktivitas jasa sektor informal (PKL) dengan pola persebaran memanjang terjadi di sepanjang atau pinggir jalan utama atau pada jalan-jalan penghubungnya.

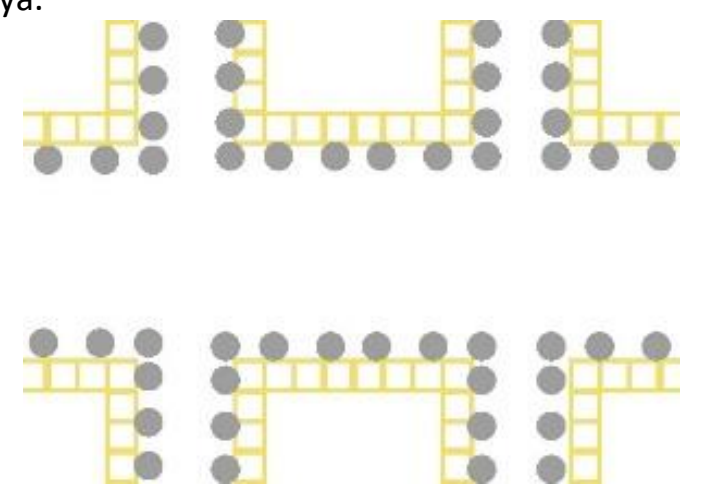

Gambar 1. Pola Persebaran Memanjang (Linier)

Sumber : McGee dan Yeung (dalam Surya, 2006) - Digambar Ulang oleh Penulis, 2020 


\section{Pola Persebaran Mengelompok (Focus Agglomeration)}

Pola persebaran ini dijumpai pada ruang-ruang terbuka, taman, lapangan dan sebagainya. biasa terjadi pada mulut jalan, disekitar pinggiran pasar umum atau ruang terbuka. Pengelompokkan ini terjadi merupakan suatu pemusatan atau pengelompokan pedagang yang memiliki sifat sama / berkaitan. Pengelompokan pedagang yang sejenis dan saling mempunyai kaitan, akan menguntungkan pedagang, karena mempunyai daya tarik besar terhadap calon pembeli. Aktivitas pedagang dengan pola ini dijumpai pada ruang-ruang terbuka (taman, lapangan, dan lainnya). Biasanya dijumpai pada para pedagang makanan dan minuman.

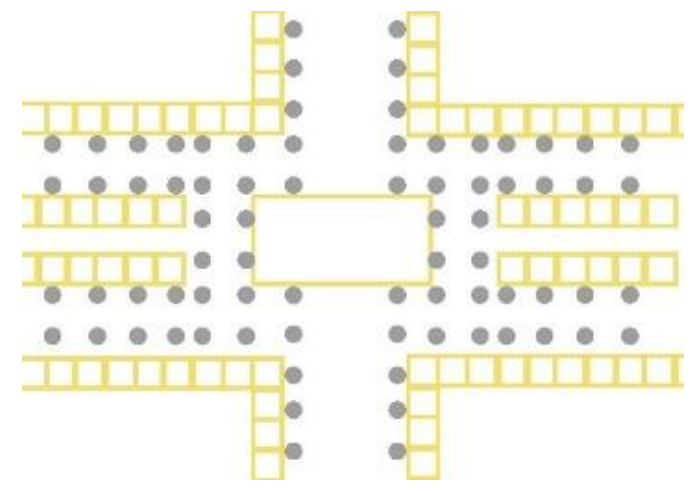

Gambar 2 Pola Persebaran Mengelompok (Focus Agglomeration)

Sumber : McGee dan Yeung (dalam Surya, 2006) - Digambar Ulang oleh Penulis, 2020

Pola Pelayanan

a. Unit PKL tidak menetap, Unit ini ditunjukkan oleh sarana fisik perdagangan yang mudah dibawa, atau dengan kata lain ciri utama dari unit ini adalah PKL yang berjualan bergerak dari satu tempat ke tempat lain.

b. Unit PKL setengah menetap, Ciri utama unit ini adalah PKL yang pada periode tertentu menetap pada suatu lokasi kemudian bergerak setelah waktu berjualan selesai (pada sore hari atau malam hari).

c. Unit PKL menetap, Ciri utama unit ini adalah PKL yang berjualan menetap pada suatu tempat tertentu. (McGee, 2006)

\section{Pola Pengelolaan}

a. Pengelolaan lokasional, Sektor informal diharapkan menempati lokasi yang sesuai dengan rencana penataan dari masing-masing kota.

b. Pengelolaan Struktural, Pemerintah kota di kawasan Asia Tenggara berdasarkan penelitian yang dilakukan oleh McGee dan Yeung (dalam Surya, 2006) lebih sering menerapkan pola pengelolaan lokasional walaupun tidak selalu berhasil. Selain bentuk pengelolaan lokasional, pemerintah kota mencoba pola pengelolaan struktural. Adapun yang termasuk dalam pengelolaan struktural adalah perizinan, pembinaan, bantuan dan pinjaman.

\section{METODE}

Salah satu metode yang digunakan adalah observasi lapangan; melakukan observasi pada tahap awal degan berkunjung ke lokasi dan juga beberapa food court lainnya yang terletak di Jakarta untuk mengetahui aktivitas yang biasanya dilakukan, sirkulasi yang dibutuhkan, dan barang-barang untuk kebutuhan food court. Observasi juga dilakukan terhadap pengguna; proses yang dilakukan antara lain melakukan observasi kepada pemilik restoran yang cukup dikenal di kawasan Mangga Besar. Restoran tersebut adalah; Restoran Selerka, Rumah Makan Nasi Tim Baru, Restoran Furama, pedagang kaki lima, dan pengguna lainnya seperti manager, supervisor, finance manager, staff, security, tenant, dan lain sebagainya. Hal tersebut dilakukan untuk mengetahui kebutuhan ruang, alur aktivitas, sirkulasi yang dibutuhkan, 
masalah yang dikeluhkan, dan lain sebagainya. Studi Pustaka juga dilakukan dalam rangka melihat studi literatur yang berhubungan dengan peraturan pembangunan di daerah Kelurahan Mangga Besar, desain food court, desain restoran, standar - standar untuk pencahayaan, penghawaan, akustik, material, dan lain sebagaianya, serta branding design untuk memperoleh teori, standar, dan aturan dalam mendesain interior maupun eksterior.

\section{DISKUSI DAN HASIL}

\section{Analisis Kawasan}

Kelurahan Mangga Besar terletak di Kecamatan Taman Sari, Jakarta Barat yang dimana di Kelurahan ini banyak terdapat tempat makan, tempat hiburan, tempat ibadah, dan juga termasuk dalam kawasan hunian. Kawasan Mangga Besar juga salah satu tempat yang banyak membantu dalam hal lapangan pekerjaan dikarenakan rata rata di daerah ini diperlukan karyawan dan karyawati untuk menjadi pegawai tempat makan. Kawasan Mangga Besar juga didominasi dengan etnis Tionghoa dan Melayu dikarenakan Kelurahan Mangga Besar dekat dengan Kawasan pecinan yaitu Glodok. Mangga Besar juga sudah Terintegrasi dengan sarana transportasi berupa halte busway Olimo, stasiun Mangga Besar, serta microlet. tidak hanya itu Mangga Besar juga termasuk salah satu tempat makan terbesar yang ada di ibukota Jakarta

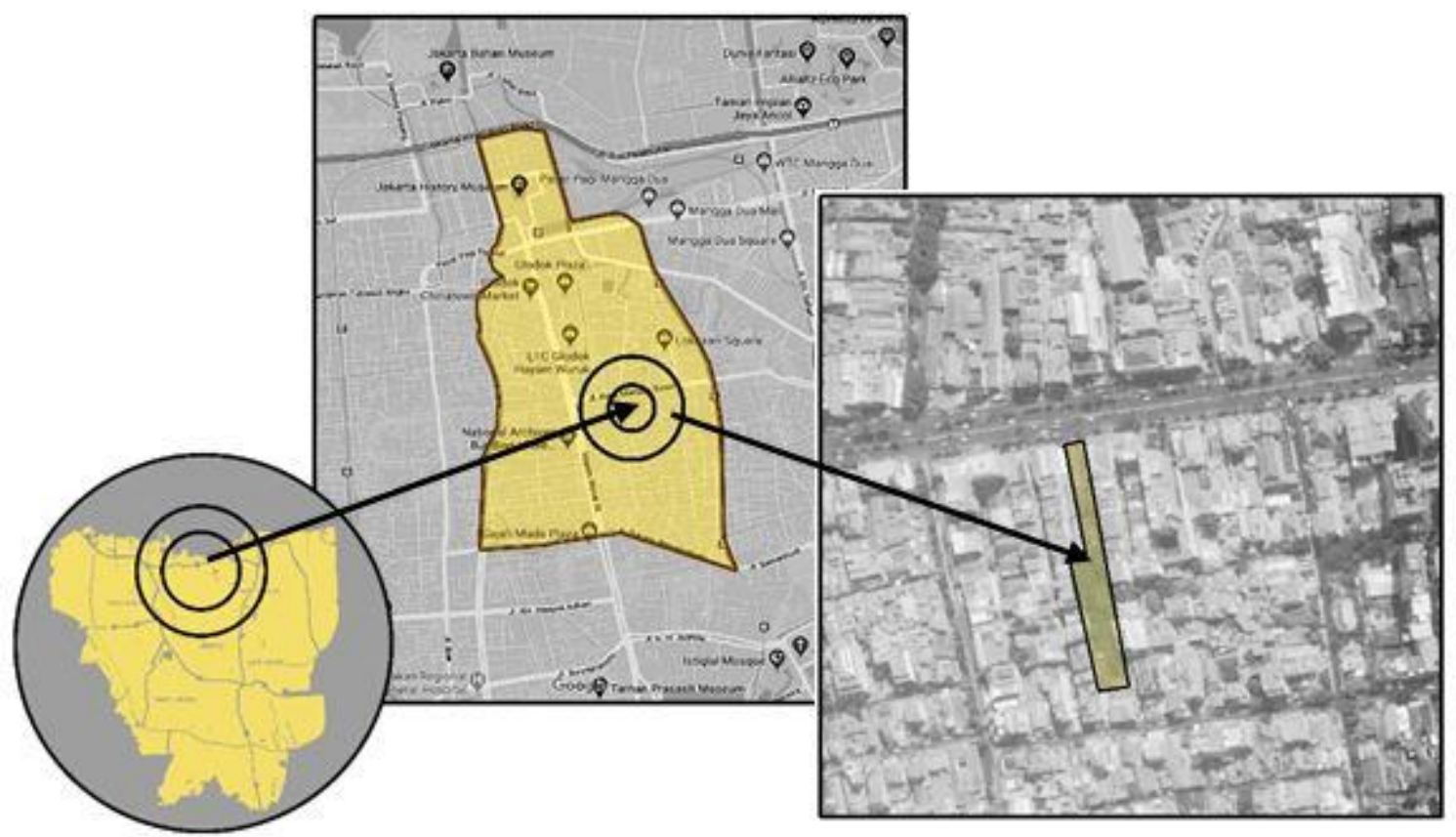

Gambar 3 Peta Lokasi Kelurahan Mangga Besar

Sumber: Googlemaps.com - Digambar Ulang Oleh Neilsen, 2020

\section{Potensi Kawasan}

a. Potensi Parawisata. Pada Kelurahan Mangga Besar banyak di temukan hiburan malam berupa club, panti pijat, tempat makan yang dimana banyaknya orang datang ke Mangga Besar untuk menghilangkan stress dapat terbukti di Mangga Besar terdapat 7 club malam , 14 panti pijat,14 pub/diskotik (Munawaroh SE, 2018)

b. Potensi Ekonomi dan Sosial. Pada Kelurahan Mangga Besar banyak sektor informal yang dimana dapat berpotensi sebagai sumber peningkatan ekonomi negara dan juga sebagai tempat penyedia lapangan kerja. Kelurahan Mangga Besar terkenal dengan kuliner kaki lima nya yang dimana kuliner kaki lima ini di manfaatkan pengguna sebagai sarana sosial (dapat bertemu dan berkomunikasi di tempat kaki lima)

c. Tapak dikelilingi oleh TOD (Transit oriented development) dengan radius 500m dan 600m ( lingkaran merah adalah stasiun Mangga Besar dan lingkaran biru adalah halte Mangga 
Besar). Tapak dikelilingi hunian yang dimana sebagai target utama food court ini. Tapak ini juga berpotensi sebagai tempat yang menyatukan sektor informal. Dikarenakan dikelilingi TOD sehingga human traffic sangat tinggi yang berpotensi meningkatkan penghasilan foodcourt.

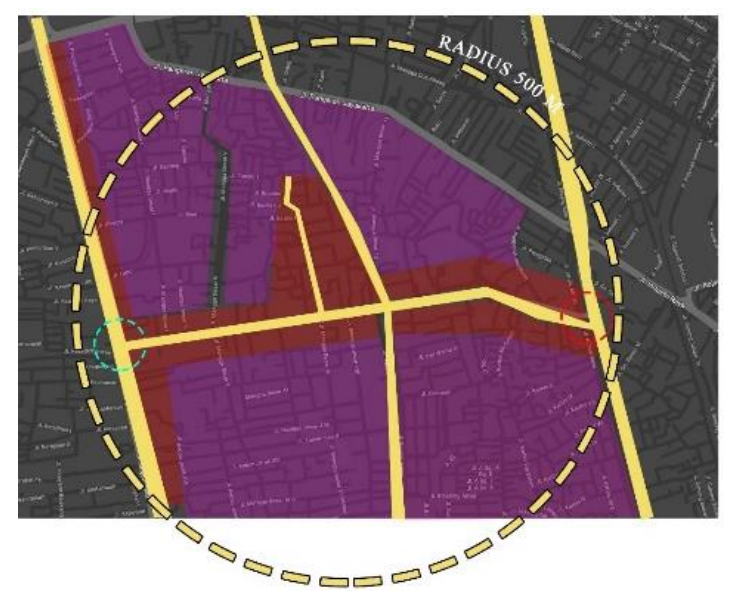

Gambar 4 Peta Lokasi Kelurahan Mangga Besar Sumber : Google.com - Digambar Ulang Oleh Neilsen, 2020

\section{Konsep Perancangan}

Konsep dari perancangan ini menggunakan metode urbanism yang dimana melihat dari perkembangan di suatu kota yaitu Jakarta. Jakarta merupakan ibukota Indonesia yang memiliki kepadatan penduduk yang sangat tinggi oleh sebab itu muncul nya permasalahan kota yaitu kemacetan yang menyebabkan stress. Oleh karena itu banyak penduduk Jakarta mencari tempat hiburan salah satu nya mencari tempat makan. Keberagaman Pasar Kuliner di Kelurahan Mangga Besar menggunakan konsep perancangan lewat informalitas yang ada di Mangga Besar, salah satu nya sistem portabel gerobak yang dapat di pindahkan dalam waktu yang singkat. Tetapi informalitas yang ada di Mangga Besar tidak terintegrasi oleh karena itu dibutuhkan sistem yang merubah informalitas yang ada di Mangga Besar agar dapat mempengaruhi human Behavior seseorang. Kemudian permasalahan yang ada di Mangga Besar sebagai acuan dalam segi merancang konsep dan bentukan ruang pada bangunan ini.

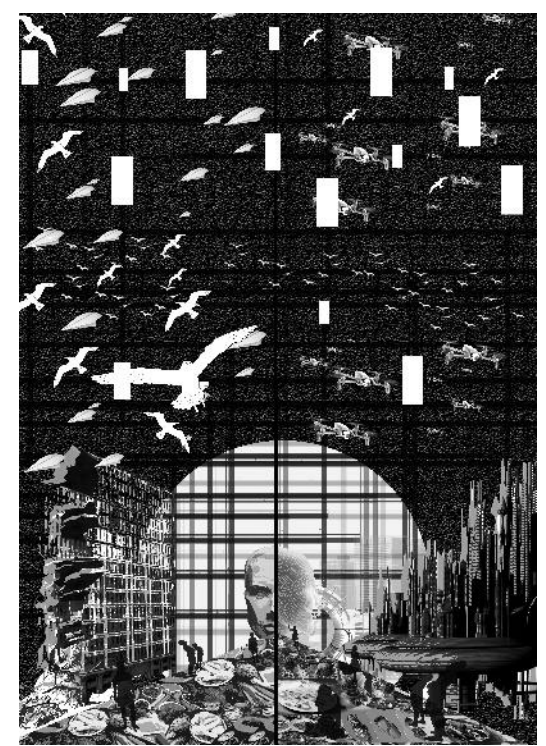

Gambar 5 llustrasi Konsep

Sumber : Penulis, 2020 

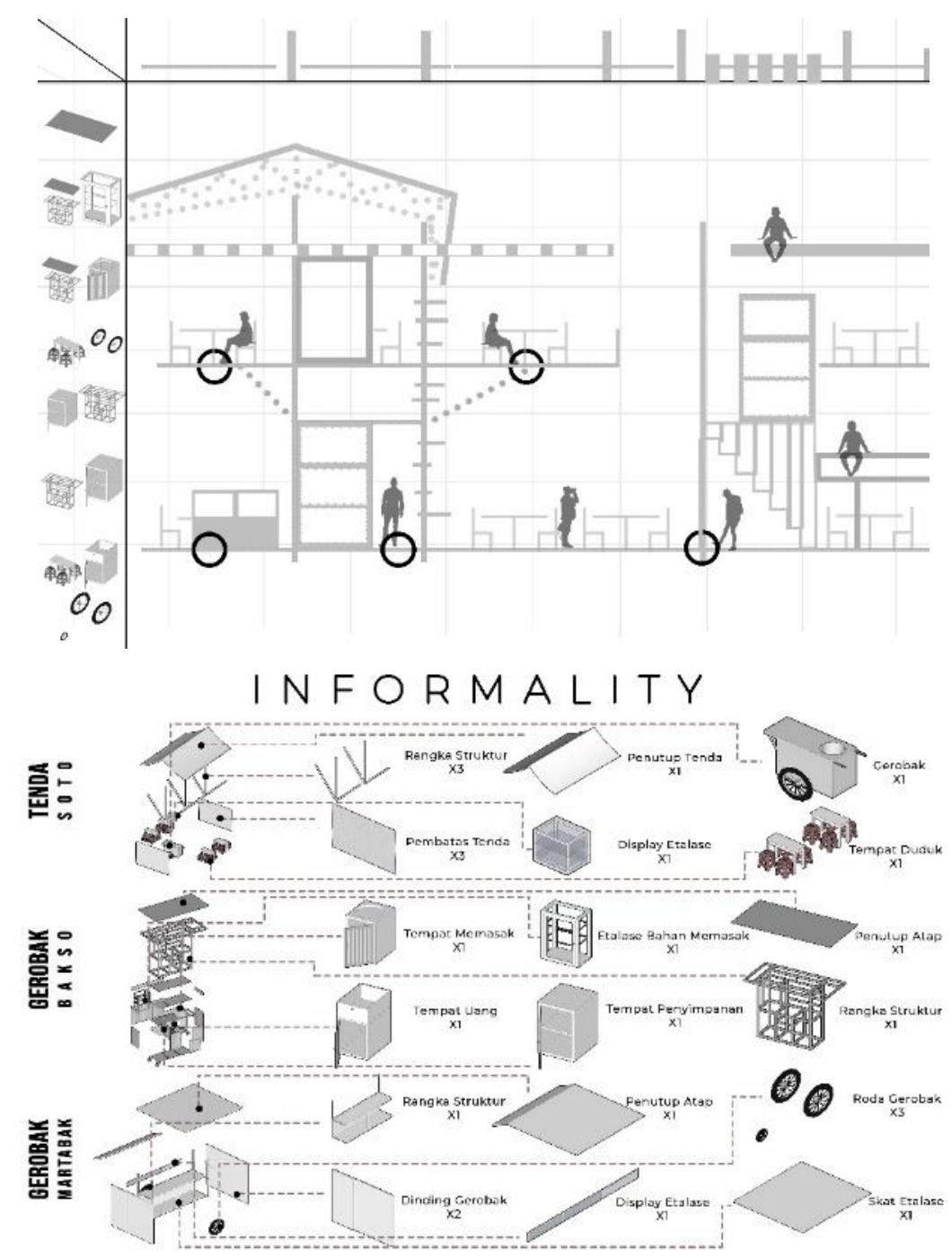

Gambar 6 Ilustrsasi Konsep dari Tipe Gerobak Sumber: Penulis, 2020

Tabel 1.Tabel Penerapan Aspek Desain dalam Rancangan

\begin{tabular}{ll}
\hline Aspek Desain & Penerapan pada Rancangan \\
\hline Human Behaviour Pada & Kebutuhan akan third place juga berbeda-beda sesuai tradisi, budaya, \\
Pola Hidup Manusia & $\begin{array}{l}\text { sejarah, dan identitas dalam suatu tempat. Contohnya di Inggris, dimana } \\
\text { negara ini jauh lebih bisa bersosialisasi dengan orang tanpa mengenalnya } \\
\text { terlebih dahulu tetapi di negara Indonesia harus ada sarana untuk } \\
\text { bersosialisasi. Oleh sebab itu, untuk menimbulkan interaksi, manusia dapat } \\
\text { diatur dengan memainkan pola warna, dan pola aksesibiltas. }\end{array}$ \\
\hline Pola Aksesibilitas & $\begin{array}{l}\text { Memainkan pola dengan cara membuat akses dengan konfigurasi radial yang } \\
\text { dimana terdapat jalur - jalur liner yang akan berakhir di sebuah titik pusat } \\
\text { (titik pusat yang di maksud adalah area publik space / tempat makan yang } \\
\text { ada di Streetfood kemudian desain tempat makan Streetfood akan di atur } \\
\text { pada bagian area makan agar orang dapat berkomunikasi lewat tata letak } \\
\text { furniture) }\end{array}$ \\
\hline Pola Warna & Warna yang akan dipakai adalah warna merah, putih, hijau yang dimana \\
& sudah di jelaskan di kajian teori.
\end{tabular}




\section{Sistem Untuk \\ Mempengaruhi Human Behavior \\ human behavior yang dimana terdapat beberapa poin yaitu: \\ 1. Kegiatan sosial yang ditampung dalam bangunan \\ 2. Fleksibilitas yang dibutuhkan pada tiap kegiatan \\ 3. "Kegiatan-kegiatan" yang mempengaruhi atau dipengaruhi \\ 4. Latar belakang dan sasaran pengguna ruang.}

Sumber: Penulis, 2020.

\section{Skema Desain}

Skema desain dimulai dari memperhatikan peraturan lingkungan berupa city guildeline, KDB, $\mathrm{KDH}, \mathrm{KLB}$, dan survey lapangan. Kemudian gubahan terbentuk dari kebutuhan ruang dan mengikuti city guideline. Kemudian dikarenakan tapak berbentuk persegi panjang kearah utara selatan sehingga massa bangunan di bagi menjadi 4 bagian dan diberi jarak $20 \mathrm{~m}$ agar memaksimalkan pengudaraan. Lalu setiap massa bangunan berukuran 20x20 untuk mengikuti metode desain berupa efisiensi pengudaraan dan penyinaran matahari. Kemudian massa bangunan lebih memfokuskan ke solid-void agar menyesuaikan dengan program dan mendapatkan kesan transparansi untuk menciptakan bangunan yang interiornya dapat dilihat dari luar bangunan. Lalu bangunan diberikan 2 akses masuk pada sisi utara dan selatan agar aksesibilitas dapat menghubungkan jalan Mangga Besar Raya dengan Mangga Besar 4e untuk menghubungkan kelurahan serta transportasi umum halte olimo dan stasiun manga besar sehingga bangunan dapat difungsikan $24 \mathrm{jam}$ dan sebagai shortcut aksesibilitas. Tidak hanya itu, bangunan diberikan vegetasi maksimal dan tempat tanaman yang di spesifikasikan untuk pengunaan pasar sehingga tanaman yang tumbuh dapat dijual kembali berupa cabai, daun bawang, bawang, kucai. Hal ini berfungsi untuk menerapkan konsep food and architecture. Bangunan ini terdiri dari 4 lantai yang ditopang dengan 4 struktur utama dan 8 struktur penunjang yang dimana setiap struktur yang terbentuk juga dapat ditanami tumbuhan merambat. Lalu terdapat juga warung kapsul portable yang dimana terinspirasi dari informality yang ada pada Mangga Besar. Warung kapsul portable ini dapat merubah fungsi sebagai area living space pada malam hari sama seperti konsep warung.

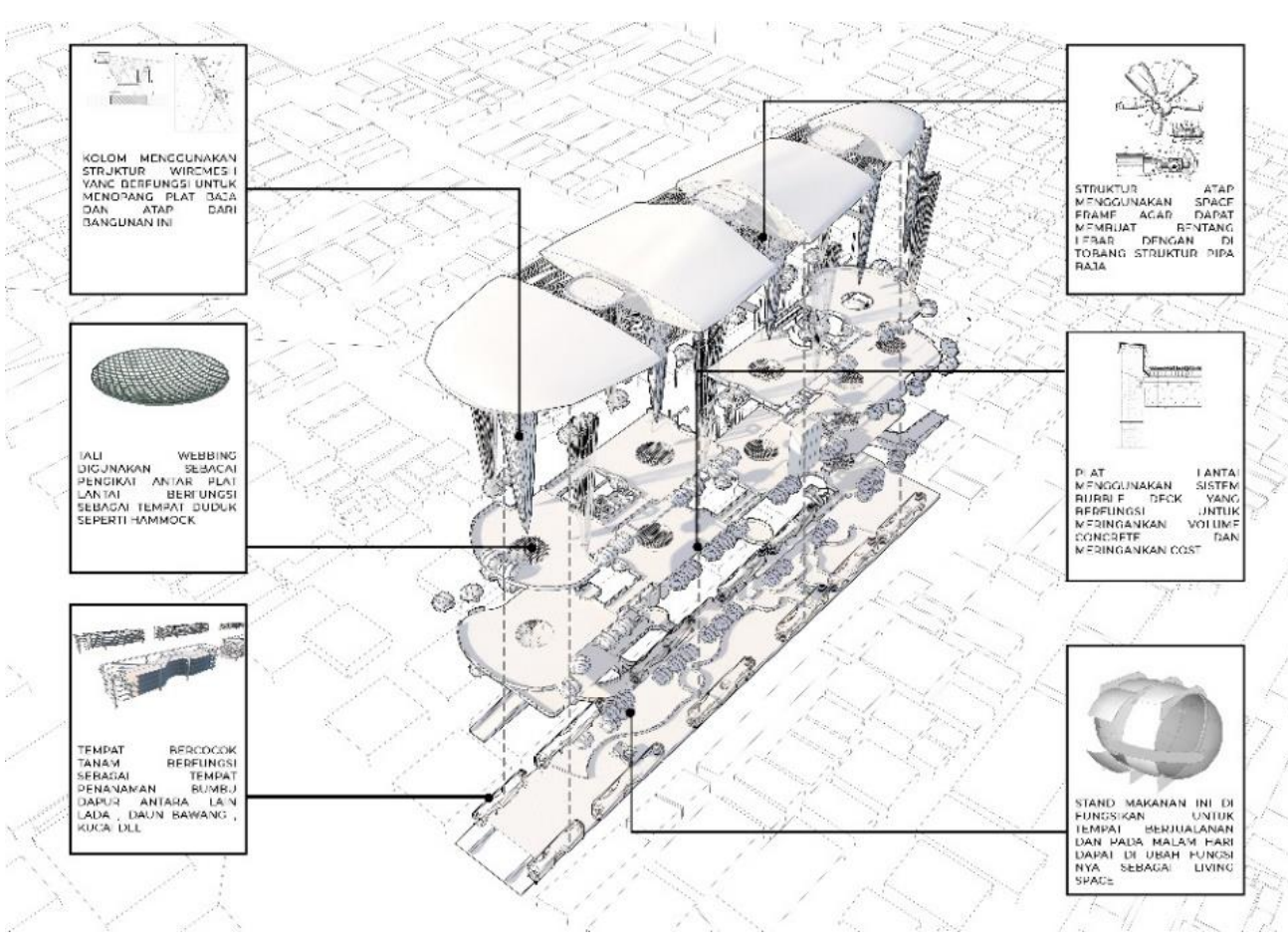

Gambar 7. Skema Desain

Sumber: Penulis, 2020 


\section{PROSES GUBAHAN MASSA}
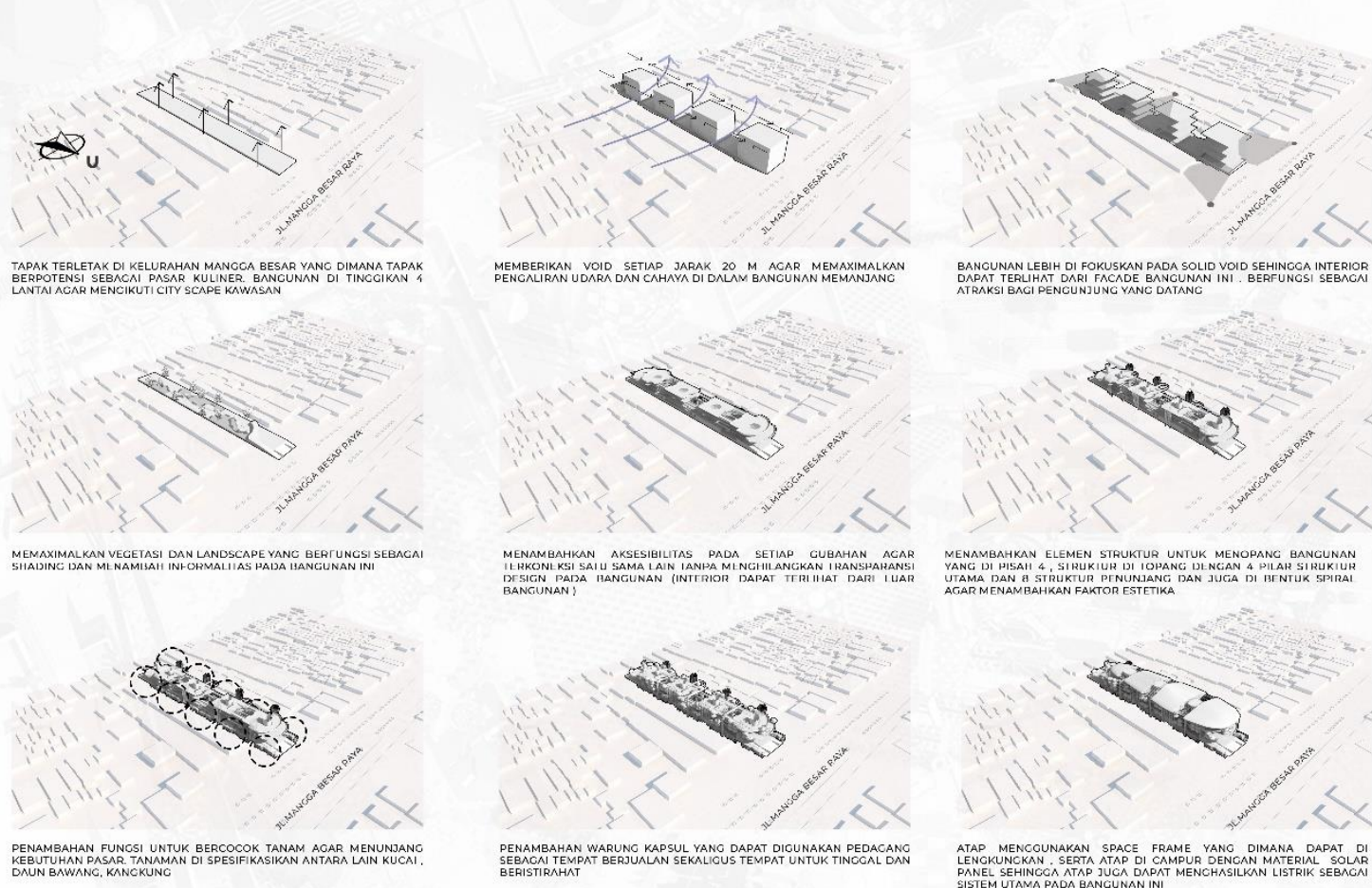

MEMBERIKAN VOID SETIAP JARAK 20 M ACAR MEMAXIMALKA
PENGALRAN UDARADAN CAHAY DIDLLAM BANGUNAN MEMANJANC
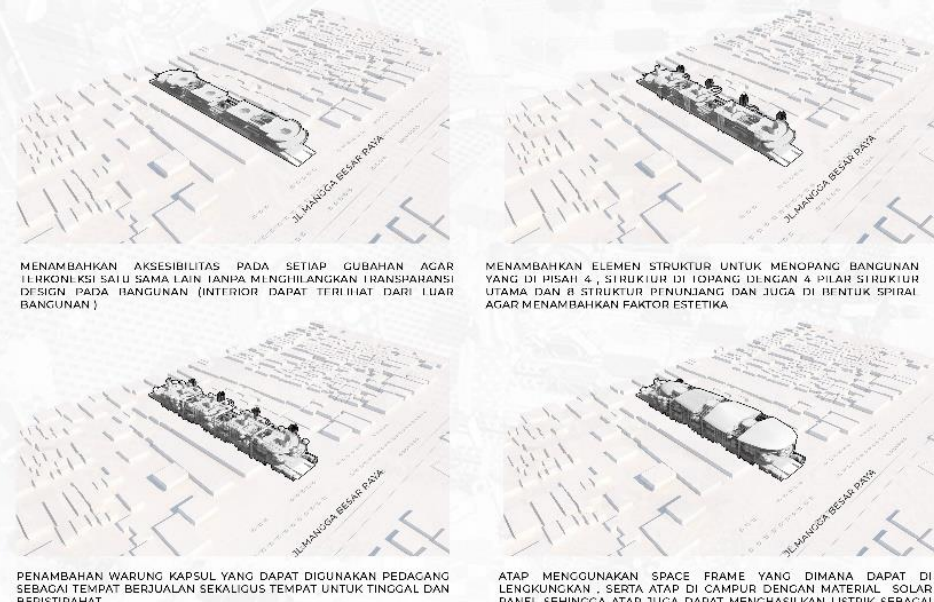

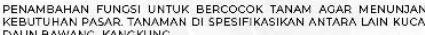

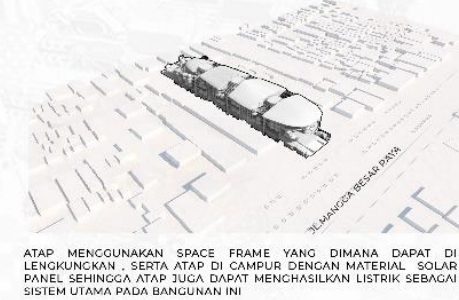

Gambar 8. Skema Desain

Sumber: Penulis, 2020

\section{Konsep Struktural dan Material}

Bangunan ini memilik 4 struktur utama dan 8 struktur penunjang yang dimana bahan utama yaitu space frame kemudian struktur utama di modifikasi dengan kawat agar menginstall tumbuhan menjalar kemudian struktur menggunakan pipa baja. Pada penutup atap menggunakan aluminium composite panel untuk pelindung dari sinar matahari dan material yang digunakan untuk penutup atap berupa struktur pipa baja / space frame.
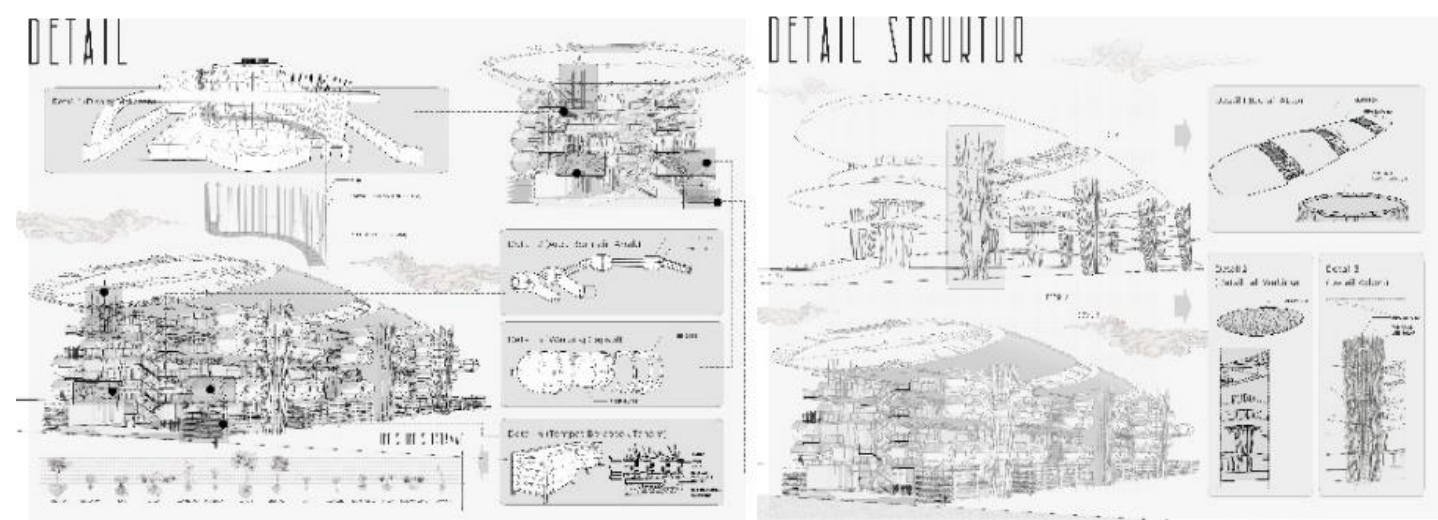

Gambar 9. Potongan Struktural dan Material

Sumber: Penulis, 2020 


\section{Implementasi Konsep Third Place}

Dalam konsep untuk mendukung tempat ketiga di Kelurahan Mangga Besar, terdapat berbagai aspek yang membuatnya menjadi sebuah tempat ketiga. Sehingga pada gambar dan tabel dibawah akan dijelaskan mengenai aspek-aspek bangunan pembentuk third place tersebut.

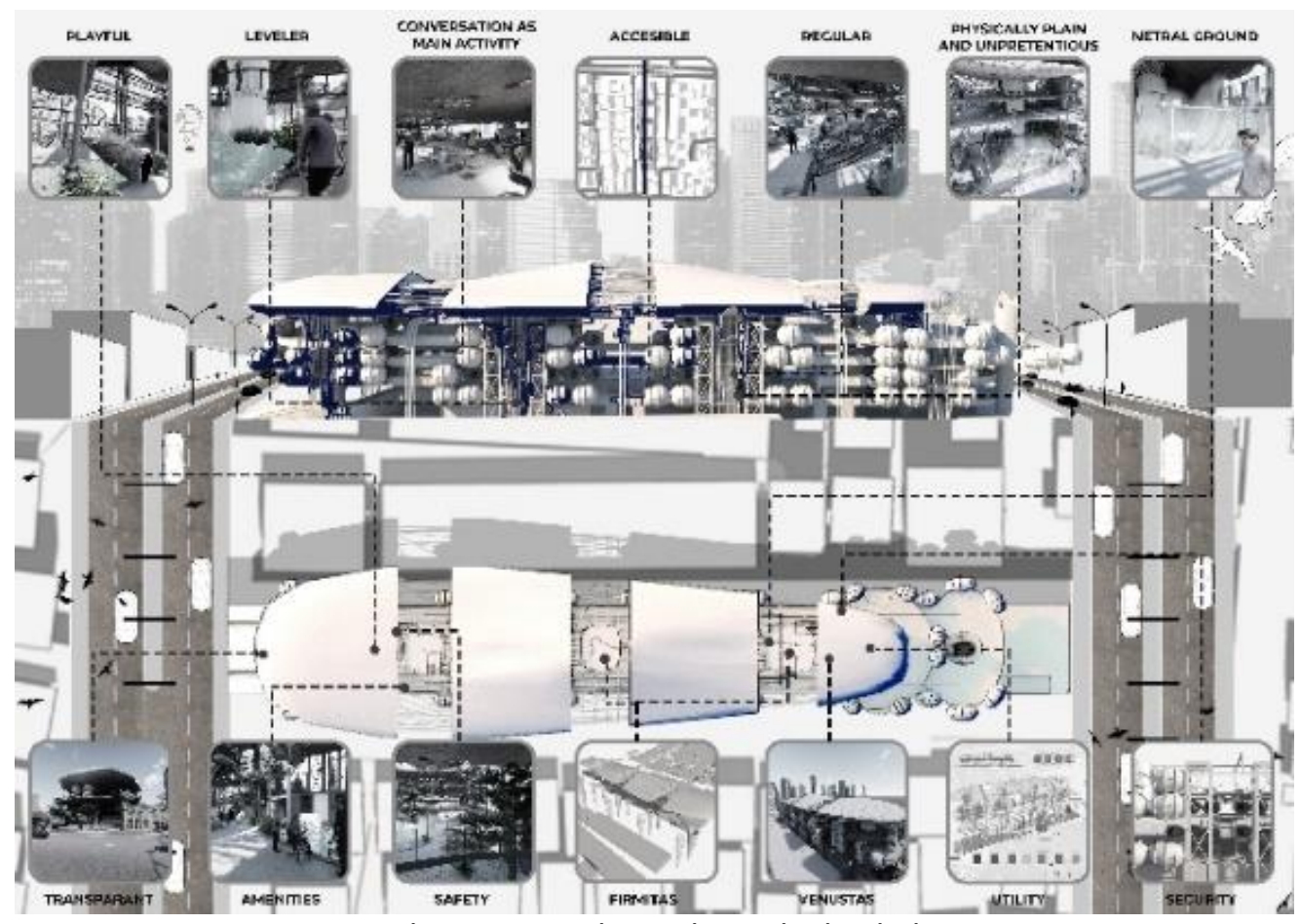

Gambar 10. Aspek Pembentuk Third Place

Sumber: Penulis, 2020

\section{KESIMPULAN DAN SARAN}

\section{Kesimpulan}

Keberagaman Pasar Kuliner di Mangga Besar terdiri dari sistem yang berfungsi untuk merubah sektor informal agar dapat merubah human behaviour seseorang yang dimana sistem yang di tawarkan antara lain sistem belt yang berfungsi mengatarkan makanan secara mandiri kemeja makan pemesan. Kemudian bangunan ini memiliki 2 akses agar dapat menggiring human traffic yang ada di Mangga Besar dari Kelurahan ke transportasi umum sehingga bangunan dapat berfungsi 24 jam. Tidak hanya itu, program yang tercipta terinspirasi dari sektor informalitas yang ada di Mangga Besar berupa sistem Portable yang dijadikan warung kapsul dimana pada malam hari dapat berubah menjadi living space untuk membuat program penunjang kehidupan user. Dengan sistem yang terintegrasi Kelurahan Mangga Besar dapat meningkatkan keseimbangan sosial antara lain terciptanya lapangan kerja baru serta meningkatkan keseimbangan sosial lewat jual beli sebagai tempat third place untuk sarana Kelurahan. Tidak hanya itu program yang ditawarkan berupa penutupan jalur lambat agar dapat memfungsikan street food agar menghilangkan parkiran illegal. Bangunan ini juga dapat sebagai sarana penghilang stress berupa mengikut program CFD (car free day) yang sering dilakukan sepanjang Jalan Sudirman sampai jalan Gajah Mada.

\section{Saran}

Jakarta merupakan kota yang memiliki kepadatan penduduk sangat tinggi oleh sebab itu timbulnya masalah berupa kemacetan, peningkatan sektor informal, dan tempat parkir illegal salah satu nya di Kelurahan Mangga Besar yang terdampak dari permasalah kota ini oleh sebab itu dibutuhkan nya sarana berupa third place yang terintegrasi dengan sistem agar 
dapat mengurangi permasalahan pada Kelurahan ini dan menciptakan Kelurahan yang ideal.

\section{REFERENSI}

Fisker, A. M., Olsen, T. D. (2008). Food, Architecture and Experience Design.

Antoniades, A., C. (1990). Poetics of Architecture: Theory of Design. New York: Van Nostrand Reinhold.

Carpaldi, E. D. (2001). Amer Psychological Ass Hetherington and Rolls 2001.

Ching, F. D.K. (1979). Human Dimension. New York: Watson Guptill D.K.Ching. n.d.

Fine, A. (2015). Handbook on Animal-Assited Therapy. California: Elsevier.

Hertzberger, H. (1991). Lesson for Student in Architecture. Rotterdam: 010 Publisher.

Hetherington, M. M., and Barbara J. Rolls. (2001). Sensory-Specific Satiety, Ther Theoretical Framework and Central Characteristics In: Why we eat What we eat, The psychology of eating.

Holdershaw, J., Gendall, P. (2008). Understanding and predicting human behaviour.

Lefebvre, H. (1991). The Production of Space. Oxford: Blackwell.

Munawaroh, M. (2018). Kelurahan Taman Sari Dalam Angka.

Oldenburg, R. (1991). The Great Good Place. New York: Marlowe \& Company.

Picon, A. (2015). Smart Cities: A Spatialized Intelligence. New Jersey: Wiley.

Richard, J. (2007). The Magazine of the American Society of Landscape Architecture. Washington,D.C.: ASLA. 